SUPPLEMENTARY MATERIAL

\title{
A new polyoxygenated farnesylcyclohexenone from Fungus \\ Penicillium sp.
}

Yabin Yang a, §, Fangfang Yang, ${ }^{\mathrm{a}}$, Lixing Zhao ${ }^{\mathrm{b}}$, Rongting Duang ${ }^{\mathrm{a}}$, Guangyi Chen ${ }^{\mathrm{a}}$, Xiaozhan $\mathrm{Li}^{\mathrm{a}}$, Qiling $\mathrm{Li}^{\mathrm{a}}$, Shaohuan Qin ${ }^{\mathrm{a}}$ and Zhongtao Ding, ${ }^{\mathrm{a}}$ *

${ }^{a}$ School of Chemical Science and Technology, Yunnan University, Kunming 650091, People's Republic of China; 'Yunnan Institute of Microbiology, Yunnan University, Kunming 650091, People's Republic of China

*Corresponding author. E-mail: ztding@ynu.edu.cn.

§These authors contributed equally to this paper. 
A new polyoxygenated farnesylcyclohexenones, peniginsengin A (1) was isolated from the fermentation of Penicillium sp. YIM PH30003, an endophytic fungus associated with Panax notoginseng (Burk.) F. H. Chen. The structure was assigned based on a combination of $1 \mathrm{D}$ and $2 \mathrm{D}$ NMR and mass spectral data. The cytotoxicity and antimicrobial activities of compound $\mathbf{1}$ were investigated.

Keywords: Penicillium sp., polyoxygenated farnesylcyclohexenone; peniginsengin

A 


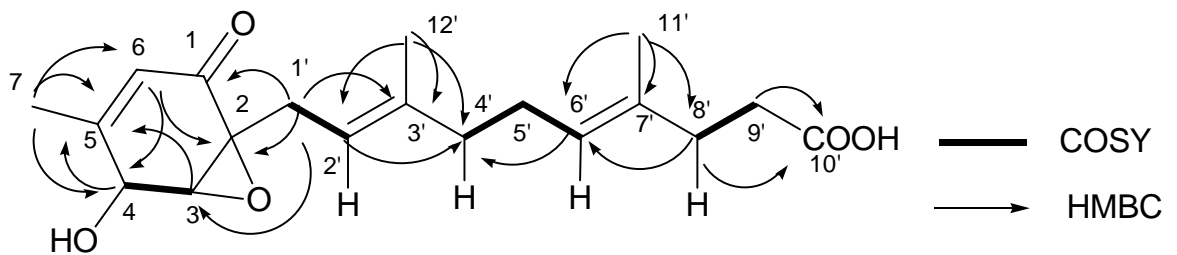

Figure S1. ${ }^{1} \mathrm{H}-{ }^{1} \mathrm{H}$ COSY and key HMBC correlations for $\mathbf{1}$.

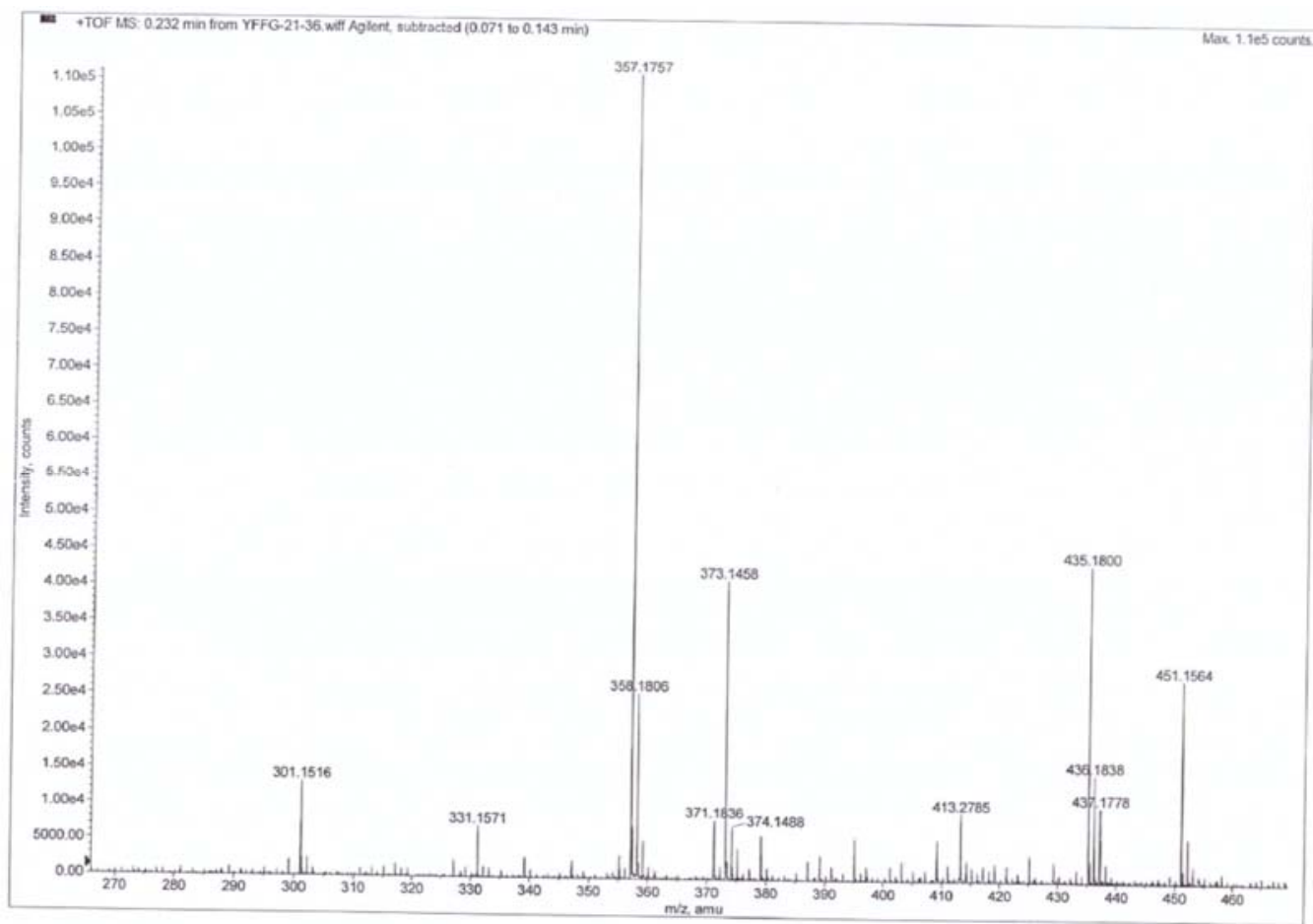

Figure S2. HR-ESIMS of compound 1 


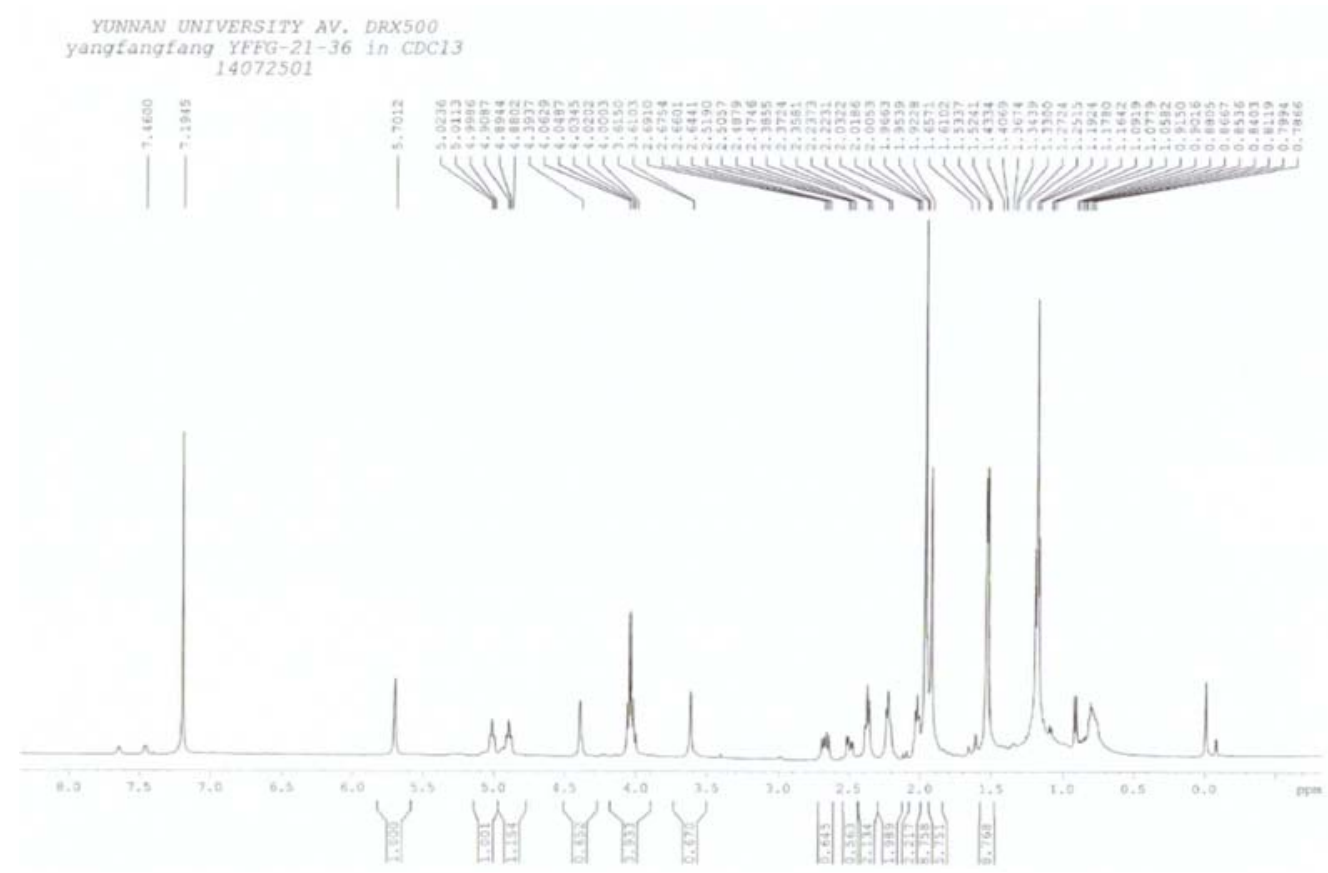

Figure S3. ${ }^{1} \mathrm{H}$ NMR of compound $\mathbf{1}$
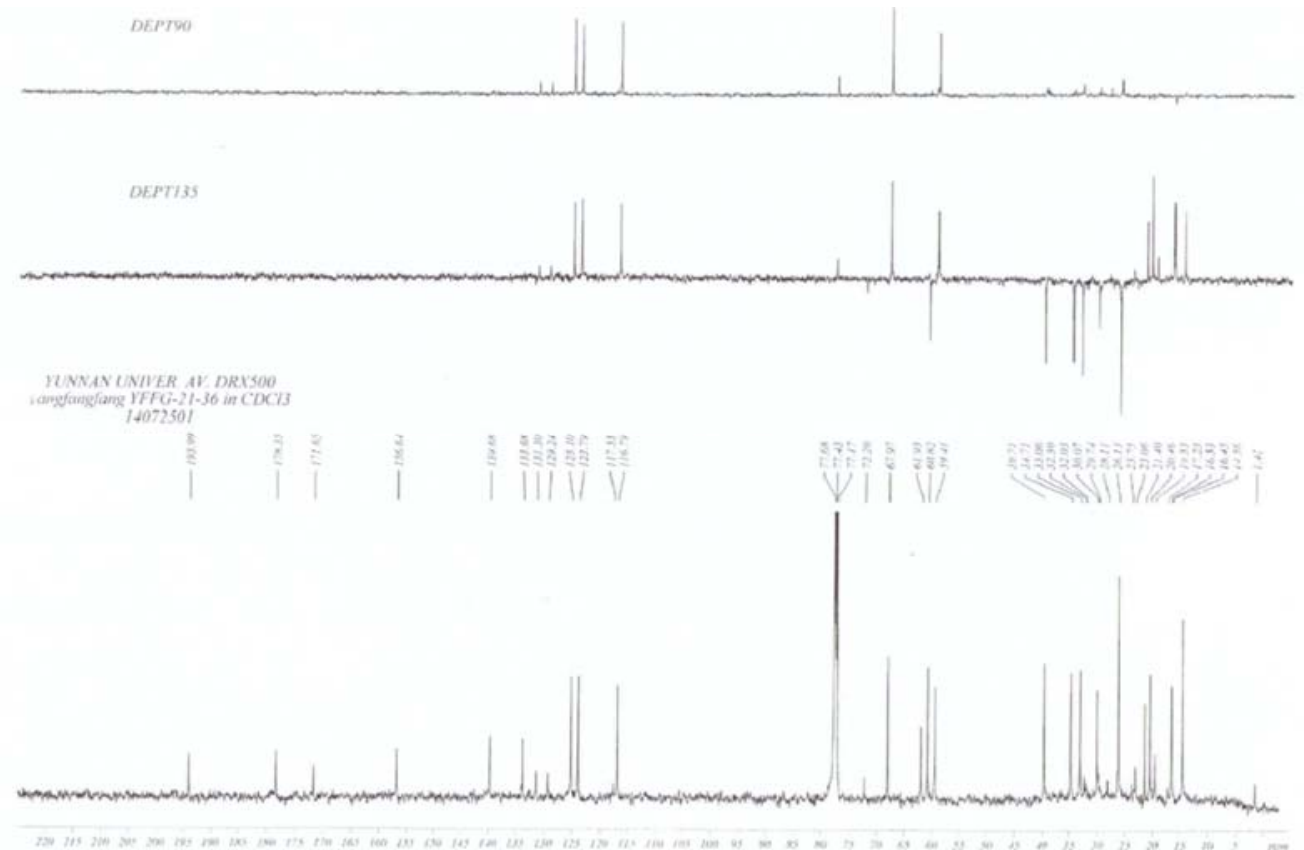

Figure S4. ${ }^{13} \mathrm{C}$ NMR of compound $\mathbf{1}$ 


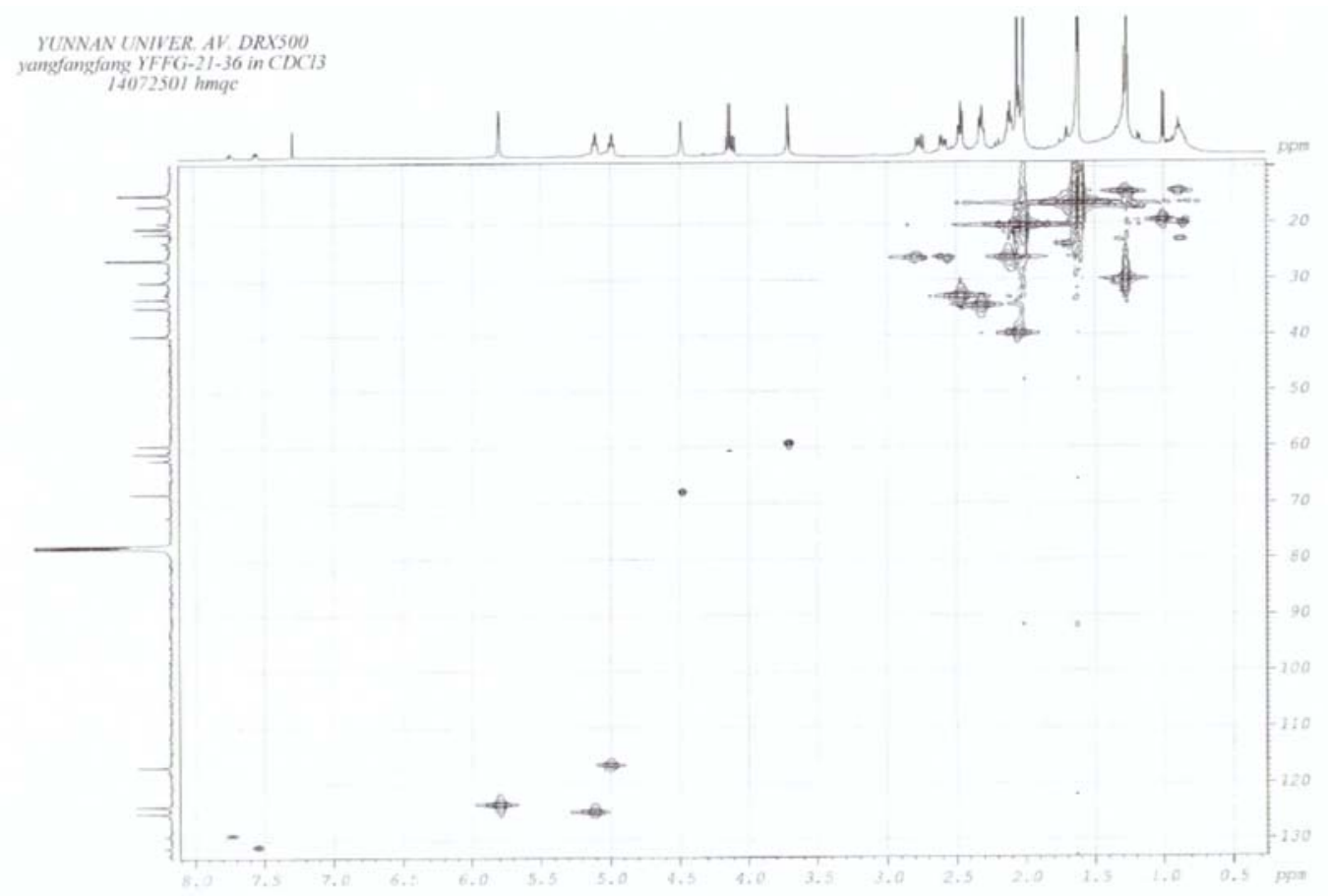

Figure S5. HMQC of compound 1

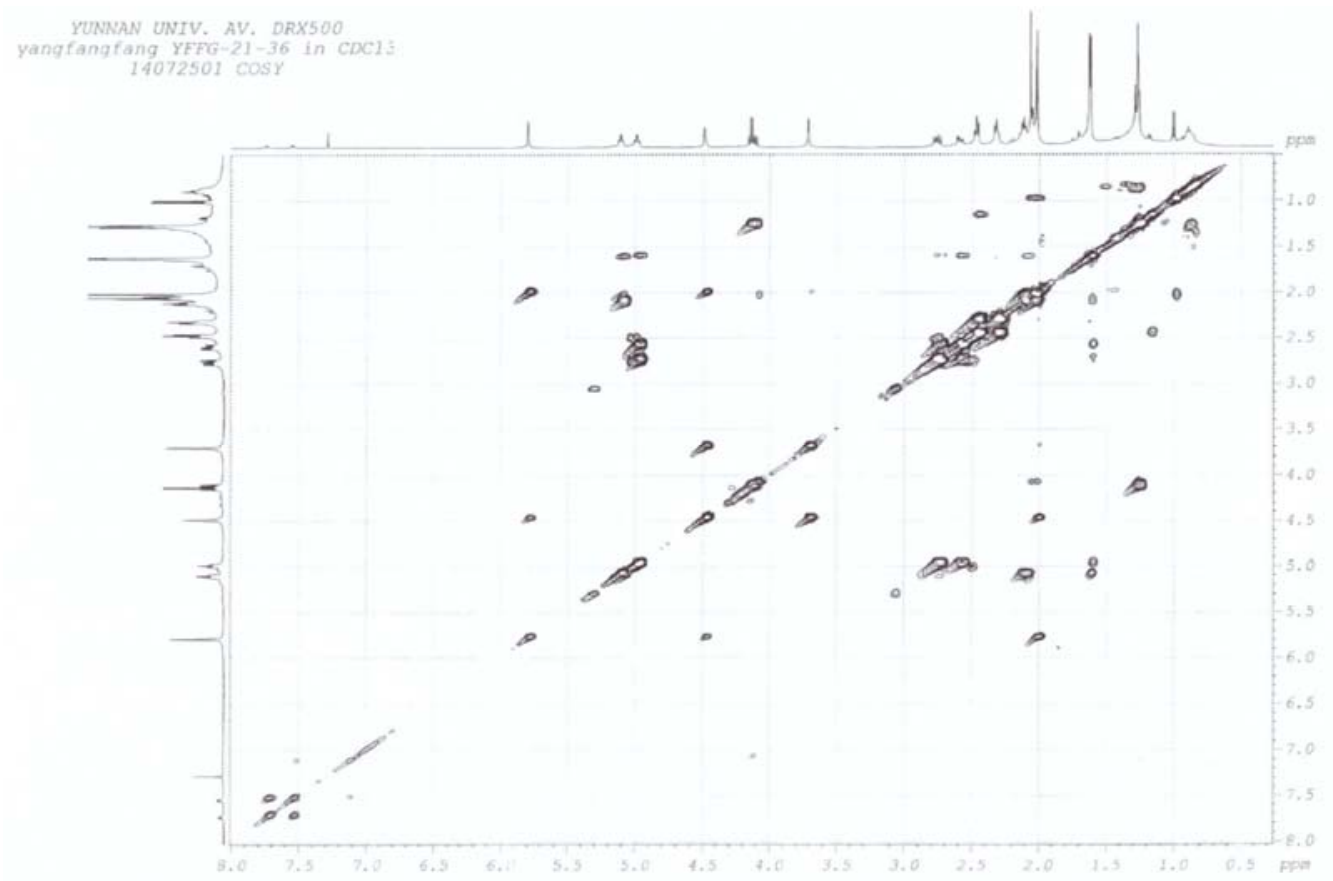

Figure S6. COSY of compound 1 


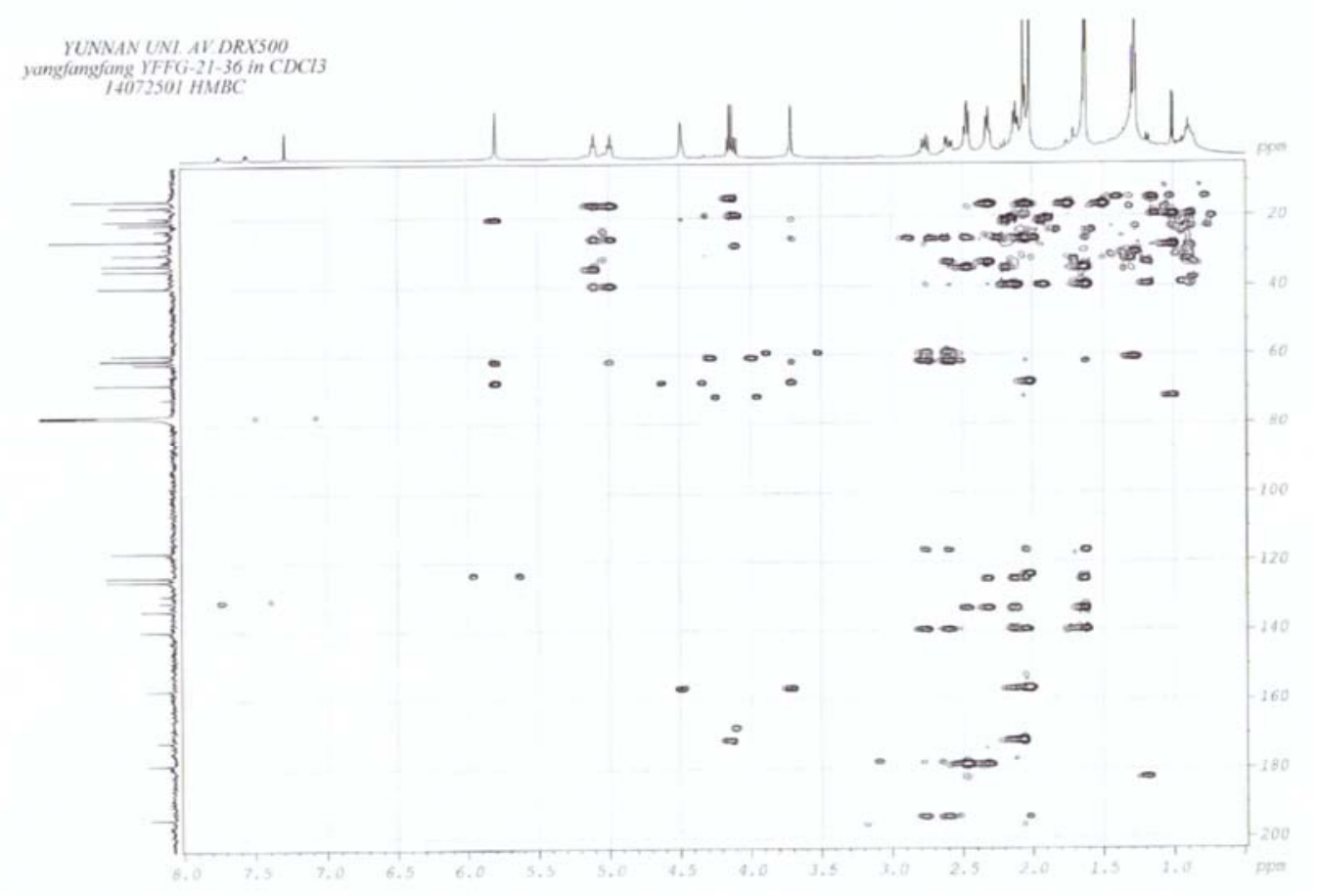

Figure S7. HMBC of compound 1

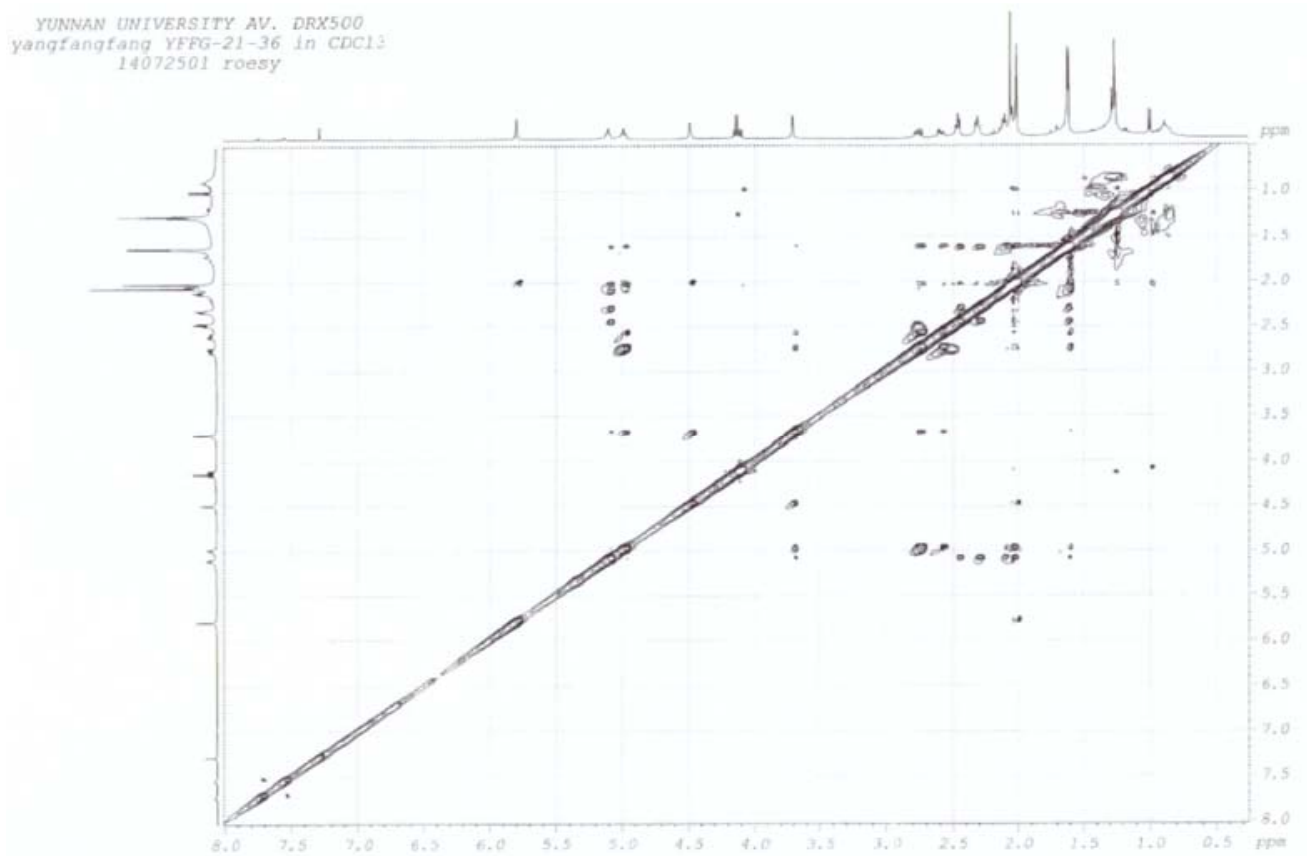

Figure S8. ROESY of compound $\mathbf{1}$ 